\title{
Propriedade intelectual, globalização e desenvolvimento: uma reflexão sobre os caminhos para o desenvolvimento sustentável da Amazônia
}

\section{Intellectual property, globalization and development: A reflection on the paths toward sustainable development in the Amazon Region}

\author{
Maria do Perpétuo Socorro Rodrigues CHAVES* \\ Marinez Gil NOGUEIRA**
}

\begin{abstract}
RESUMO
Este ensaio apresenta uma abordagem sobre as conseqüências econômicas e sociais do sistema internacional de propriedade intelectual para os países em desenvolvimento, evidenciando a situação brasileira. Analisa a relação entre o sistema de propriedade intelectual e a busca de um desenvolvimento sustentável para a Amazônia. Apresenta um breve histórico da formação do sistema internacional de propriedade intelectual, ressaltando os conceitos relativos à propriedade industrial com ênfase nas patentes. Busca refletir sobre a perspectiva de desenvolvimento sustentável para a Amazônia e os obstáculos da legislação de propriedade intelectual, com destaque para a questão do acesso aos recursos genéticos da biodiversidade amazônica brasileira.
\end{abstract}

Palavras-chave: desenvolvimento sustentável; inovação tecnológica; propriedade intelectual.

\begin{abstract}
This essay presents an approach to the economical and social consequences of the intellectual property international system in developing countries, with an emphasis on the Brazilian case. It analyzes the relationship between the intellectual property system and the search for sustainable development in the Amazon region. It provides a brief report on the formation of the international intellectual property system, pointing out concepts pertinent to industrial property, with an emphasis on patents. It also contemplates a sustainable development prospect for the Amazon and the obstacles posed by intellectual property legislation, calling attention to the right to use the genetic resources of the Brazilian Amazonian biodiversity issue.

Key-words: sustainable development; technological innovation; intellectual property.

\footnotetext{
" Docente do Departamento de Serviço Social da Universidade Federal do Amazonas, Doutora em Política Científica e Tecnológica UNICAMP/CIRED, Coordenadora do Grupo Interdisciplinar de Estudos Sócio-ambientais e de Desenvolvimento de Tecnologias Apropriadas na Amazônia/Grupo Inter-Ação. Contato: socorro.chaves@ig.com.br.

"* Docente do Dep. Serviço Social da Universidade Federal do Amazonas, Doutoranda em Biotecnologia UFAM/INPA. Pesquisadora do Grupo Inter-Ação. Contato: mgnogueira@vivax.com.br.
} 


\section{Introdução}

Mudanças institucionais significativas foram impulsionadas pela dinâmica econômica globalizada. Como exemplo, ressalta-se o surgimento da Organização Mundial do Comércio - OMC, que objetivou a criação gradativa de um ambiente livre para o intercâmbio comercial entre os vários países capitalistas. Conforme Singer (1998), a globalização não é um processo novo, mas, a partir das duas últimas décadas do século XX, foi reforçado com o advento do capitalismo financeiro, evidenciando a tendência do seu desenvolvimento em escala mundial sob a égide da hegemonia do neoliberalismo, incorporando as diversas regiões do globo.

Para Santos (2003, p. 1), as profundas transformações ocorridas no sistema econômico mundial podem ser visualizadas em dois fenômenos interligados, a globalização econômica e a criação de blocos econômicos regionais ${ }^{1}$, que são aparentemente contraditórios ${ }^{2}$. A necessidade de certa padronização da legislação dos países componentes dos blocos econômicos em alguns assuntos e, principalmente, em relação à formação de um sistema mundial de propriedade intelectual, revela a força desse movimento ao mesmo tempo contraditório e complementar entre globalização e regionalização de blocos econômicos.

Nesse contexto de intensificação da globalização econômica, destacam-se as discussões sobre o desenvolvimento tecnológico e, em conseqüência, sobre a proteção à propriedade intelectual. Segundo Barbosa (2003), a Convenção da OMPI (Organização Mundial da Propriedade Intelectual), define como propriedade intelectual a soma dos direitos relativos às obras literárias, artísticas e científicas, ou seja, relativos às invenções em todos os domínios da atividade humana (as descobertas científicas, os desenhos e modelos industriais, as marcas industriais, comerciais e de serviço) bem como às firmas comerciais e denominações comerciais, à proteção contra a concorrência desleal e todos os outros direitos inerentes à atividade intelectual nos domínios industrial, científico, literário e artístico.

Assim, compreende-se que a fase atual de internacionalização da economia forçou os países a buscarem uma harmonização entre suas diversas legislações. Este esforço foi verificado no avanço das negociações que envolvem leis que regem a propriedade intelectual, criando um sistema internacional de propriedade intelectual orquestrado pela OMC mediante a aprovação do chamado acordo TRIPS ${ }^{3}$.

Segundo Macedo (2000), o objetivo da propriedade intelectual centra-se na promoção do progresso científico e tecnológico e das artes aplicadas, mediante a concessão de monopólio temporal de direitos exclusivos de comercialização de produtos e processos aos seus inventores. Assim, a propriedade intelectual engloba os seguintes elementos: propriedade industrial, direitos autorais e outros direitos sobre bens imateriais. As patentes compõem um subsistema do sistema internacional de propriedade industrial, visualizadas como um tipo de instrumento de desenvolvimento tecnológico.

\begin{abstract}
A patente é uma unidade contraditória: protege o inventor, mas também o desafia ao facilitar a geração de novas invenções por terceiros, induzindo o seu próprio titular a prosseguir inventando para se manter à frente de seus competidores. Em outras palavras, a propriedade temporalmente limitada e o interesse público da informação divulgada - razão de ser público e privado da patente -, é um instrumento de promoção do desenvolvimento tecnológico (MACEDO, 2000, p. 20).
\end{abstract}

\footnotetext{
${ }^{1}$ Conforme Santos (2003), ao mesmo tempo em que ocorre a globalização, são formados blocos econômicos entre países, tanto sob forma de zonas de livre comércio, quanto sob o formato de mercados comuns. Os blocos econômicos são espaços econômicos comuns que visam a livre movimentação de bens, serviços, capitais e pessoas, além de buscar assegurar a coordenação das políticas macroeconômicas, até mesmo com a unificação do padrão monetário, ainda, busca certa padronização da legislação dos países componentes em alguns assuntos. Este comportamento econômico reflete-se na consolidação de tais blocos, em que se destacam a Comunidade Econômica Européia (União Européia, após o Tratado de Maastricht) e o North American Free Trade Agreement (NAFTA). Nesse processo de formação de blocos econômicos, foi criado, em 1991, na América do Sul, por meio do Tratado de Assunção, o chamado Mercado Comum do Sul, o qual passou a ser conhecido pela sigla MERCOSUL. Esse Mercado é formado pela Argentina, Brasil, Paraguai e Uruguai, tendo como principal objetivo coordenar políticas macroeconômicas entre os Estados membros, visando melhorar a capacidade competitiva frente ao mundo globalizado.

${ }^{2}$ Santos (2003, p. 1) explica que "a globalização - que exige ampla liberdade de comércio - e o surgimento dos blocos econômicos - que pressupõe algum sistema de preferência entre os participantes, contrariando a lógica liberal - embora apresentem essa aparente contradição, todavia são processos interligados e complementares. Através da participação em blocos, os estados podem reforçar a sua capacidade competitiva para enfrentar a concorrência acirrada em mercados globalizados". ${ }^{3}$ Para Barbosa (2003), o novo acordo sobre Propriedade intelectual, denominado TRIPS (Agreement on Trade-Related Aspects of Intellectual Property Rights) resulta de uma longa elaboração no âmbito do GATT (General Agrement on Tariffs and Trade). Constatou-se um abandono do foro tradicional das discussões de propriedade intelectual, a OMPI, e foi lançado um processo de negociação do tema no âmbito do GATT, através da Rodada do Uruguai, que resultou no acordo TRIPS da OMC.
} 
Não são poucos os autores que enfatizam a face positiva do sistema de propriedade intelectual no que se refere ao incentivo à inovação tecnológica ${ }^{4}$. Contudo, também não são poucos os autores que consideraram o sistema de patentes como criador de monopólios, limitando o crescimento e concentrando riquezas nas mãos de um número reduzido de países. Essa é a verdadeira face da globalização da economia, a ampliação da exclusão social diante de uma reestruturação produtiva que vem criando o desemprego estrutural e a precarização do trabalho.

Desse modo, concorda-se com o pensamento de Varella (2004a, p. 1) que, ao analisar as relações dos países do Norte e do Sul no âmbito da OMC, defende que "em um contexto de expansão das desigualdades internacionais, as normas de proteção intelectual não estimulam a inovação tecnológica no Sul, ao contrário, elas aumentam a dependência tecnológica e o fluxo financeiro do Sul para o Norte".

Sob essa perspectiva, esse trabalho tem como objetivo apresentar indicações das possíveis conseqüências econômicas e sociais do sistema internacional de propriedade intelectual para os países em desenvolvimento, evidenciando a situação brasileira. Diante desse aporte teórico, busca-se refletir a relação desse sistema de propriedade intelectual com a busca de um desenvolvimento sustentável para a Amazônia. Nesse sentido, este trabalho está estruturado em três partes. Na primeira, será apresentado um breve histórico da formação do sistema internacional de propriedade intelectual, ressaltando os conceitos relativos à propriedade industrial com ênfase nas patentes. A segunda parte constitui-se de uma síntese dos argumentos de Varella (2004a) sobre as perdas econômicas e sociais dos países do sul, impostas pelo sistema mundial de propriedade intelectual. E, por último, apresenta-se uma reflexão sobre a perspectiva de desenvolvimento sustentável para a Amazônia e os obstáculos da legislação de propriedade intelectual, com destaque para a questão do acesso aos recursos genéticos da biodiversidade brasileira.

\section{Sistema Internacional de Propriedade Intelectual: breve histórico}

De acordo com Santos (2003), no Direito Internacional, a criação da OMPI - Organização Mundial de Propriedade Intelectual - revela a preocupação internacional com a propriedade intelectual. A OMPI foi estabelecida por uma convenção em Estocolmo, em 1967, que passou a ser conhecida como a Convenção de Estabelecimento da Organização Mundial da Propriedade Intelectual, e entrou em vigor apenas em 1970. A OMPI foi estabelecida há poucas décadas, contudo, a origem dessa Organização está em 1883, na convenção de Paris ${ }^{5}$ para a Proteção da Propriedade Intelectual, e em 1886 na convenção de Berna ${ }^{6}$ para a Proteção de Trabalhos Artísticos e Literários.

Ao se falar em propriedade intelectual, é possível destacar duas categorias distintas: a) propriedade industrial e b) direitos autorais. A propriedade industrial compreende as invenções, as marcas registradas e os desenhos industriais. Os direitos autorais estão compreendidos no campo da literatura e das artes e podem ser expressos em diferentes formas, tais como: palavras, símbolos, música, quadros, objetos tridimensionais, ou através da combinação deles. Destaca-se que as leis de proteção ao direito autoral

regulam trabalhos literários (livros, poemas, contos, ...), musicais, coreógrafos, artísticos (pintura, escultura, desenho,...), fotográficos, audiovisuais (filmes, desenhos animados, peças de teatro, programas de televisão,...), além de mapas e desenhos técnicos (santos, 2003, p. 2).

Para os fins desse trabalho, será enfatizada apenas a propriedade industrial, que, segundo Macedo (2003, p. 3), "abrange Patentes de Invenção e de Modelo de Utilidade, Marcas, Desenhos Industriais, bem como a Repressão às falsas Indicações Geográficas e à Concorrência Desleal

\footnotetext{
${ }^{4}$ A importância da inovação ou do progresso tecnológico a ela inerente foi retratada teórica e empiricamente há vários anos. Nas primeiras décadas do século XX, o economista Joseph Schumpeter advogou a importância do processo de inovação para o crescimento do produto. Já em meados do século, Robert Solow apresentou a teoria de que sem progresso tecnológico não há crescimento sustentado do produto per capita. Assim, a importância da inovação tecnológica está na base da teoria do crescimento econômico (FONSECA, 2001).

${ }^{5}$ Convenção da União de Paris (CUP) foi instituída em 20 de março de 1883. É um tratado multilateral básico que tem como objetos os institutos da propriedade intelectual (patentes em geral, marcas em geral, indicações de procedência e proteção à concorrência desleal). O Brasil é não só signatário dessa convenção, mas, também, um dos países fundadores (MACEDO, 2000).

${ }^{6}$ De acordo com Barbosa (2003), a Convenção de Berna data, como a de Paris, do século XIX, e tem sido o centro das discussões sobre a padronização dos direitos autorais. Assim, a internacionalização do Direito Autoral é fenômeno quase tão antigo quanto o da Propriedade Industrial.
} 
(o chamado 'segredo industrial'/know-how)". Cabe ressaltar que as criações na área da agricultura - como as novas variedades de plantas - são tratadas em legislações específicas geridas pela União Internacional para a Proteção das Obtenções Vegetais (UPOV), que é uma organização que mantém estreita relação com a OMPI. As criações intelectuais na área de software e topologia (circuitos integrados) são protegidas por regulamentações específicas também no âmbito da OMPI.

No campo da propriedade industrial, as patentes são vistas como formas de proteção da criação intelectual (invenção) frente à competição tecnológica de um mercado globalizado. A competitividade atual do mercado internacional impõe a necessidade do lançamento de produtos cada vez mais sofisticados tecnologicamente, além de custos cada vez menores. Essa ambiência competitiva tem impulsionado as empresas e as instituições de pesquisa a proteger suas criações. A motivação para o patenteamento das criações está diretamente relacionada ao retorno financeiro do investimento em pesquisa e desenvolvimento (P\&D) realizado pelos inventores. Nesse sentido, o sistema de patentes possibilita a criação de condições favoráveis para o investimento de capital de risco na transformação de uma invenção em inovação ${ }^{7}$. Desse modo, entende-se por patente: "um documento, expedido por um órgão governamental que descreve a invenção ou o modelo de utilidade e cria uma situação legal em que qualquer dessas criações, quando patenteada, só pode ser explorada (produzida, usada, vendida) com a autorização de seu proprietário" (MACEDO, 2003, p. 2).

Conforme Macedo (2003), a proteção conferida pela patente é limitada no tempo. Na maioria dos países, a vigência da proteção é de 20 anos, a partir da data do depósito do pedido de patente (inclusive no Brasil). Na relação entre o Estado e o detentor da patente ocorre uma troca, em que o titular, ao ter assegurado seu monopólio temporal, compromete-se a divulgar sua invenção. Essa situação diferencia-se do segredo de negócio (Trade Secret), que pode ser entendido como uma espécie de informação, que, se mantida em segredo, confere ao seu detentor uma vantagem competitiva em relação aos concorrentes. A patente é visualizada como um instrumento que contribui para a disseminação de novos conhecimentos, pois o direito conferido ao titular para o uso exclusivo da sua invenção por um limitado período de tempo não é concedido em troca de nada. O inventor deve revelar os detalhes de sua invenção à sociedade, mediante a informação contida em um documento de patente, possibilitando o desenvolvimento de pesquisa e experimentação (exceto, é claro, para uso comercial) por todo o tempo que vigorar a patente. "O período de tempo durante o qual o detentor da patente possui os direitos exclusivos sobre o uso de sua invenção favorece as condições que facilitam o desenvolvimento e a utilização eficiente das inovações patenteadas" (idem, p. 2).

Assim, em todas as leis nacionais, os requisitos básicos necessários para o Estado consentir a proteção de uma invenção por meio de patentes são: a) novidade, b) atividade inventiva e c) aplicação industrial.

Conforme Varella (2004a), a conclusão do processo de generalização do sistema de patentes nos países desenvolvidos de economia de mercado ocorreu nos anos de 1970 e 1980. Com a assinatura do acordo TRIPS em 1994 (passando a vigorar para os países desenvolvidos a partir de 1996 e para os países em desenvolvimento a partir de 2000), pode-se dizer que um sistema mundial de propriedade intelectual foi consolidado.

A questão da divulgação de informação tecnológica, contida em documentos de patentes, é sempre difundida como aspecto positivo do sistema de propriedade industrial pelos defensores do Sistema Internacional de Propriedade Intelectual. Contudo, não se pode considerar de forma absoluta que a patente possibilite transferência tecnológica ${ }^{8}$ pela obrigatoriedade de divulgação da criação pelos seus inventores. Outros fatores relacionados às diferenças socioeconômicas entre países desenvolvidos e em desenvolvimento (países do Norte e do Sul) incidem na consolidação das desigualdades internacionais de apropriação e desenvolvimento de tecnologia no mundo

\footnotetext{
${ }^{7}$ Para Macedo (2000, p. 22), no campo da propriedade industrial pode-se dizer que a inovação tem origem na invenção, sendo esta compreendida como uma nova solução para um problema técnico de produção (tal problema pode ser antigo ou novo). Assim, uma inovação é uma invenção que prosseguiu "até a comercialização da própria invenção ou da mercadoria que a contém, pois o processo inovativo por definição, contém sempre a comercialização".

${ }^{8}$ Refere-se ao acesso à tecnologia, ou seja, é o acesso ao conhecimento (muito confundido com acesso à mercadoria). Não é possível dominar qualquer tecnologia sem passar por um processo de aprendizado. Assim, transferência tecnológica refere-se ao processo de tornar acessível à informação tecnológica. E por informação tecnológica entende-se "todo conhecimento de natureza técnica, econômico, gerencial, etc. que, por sua aplicação, favoreça o progresso na forma de aperfeiçoamento e inovação" (SILVA, 2003, p. 3).
} 
atual da globalização econômica. Essa questão será aprofundada no próximo item, em que serão tratados os argumentos de Varella (2004) sobre a expansão das desigualdades internacionais decorrentes das normas mundiais de proteção da propriedade intelectual. Cumpre ressaltar que, para esse autor, o Sistema Internacional de Propriedade Intelectual passará a reafirmar e a expandir as desigualdades entre países desenvolvidos e em desenvolvimento.

\section{Propriedade Intelectual pós-acordo TRIPS: desigualdades de domínio tecnológico entre países do sul}

De acordo com Santos (2003), o TRIPS é um acordo de "direitos mínimos", um piso mínimo para as legislações nacionais, que regula a proteção dos direitos de propriedade intelectual, incluindo patentes, direitos autorais, marcas registradas, indicações geográficas e desenhos industriais. O acordo impõe, mediante normatização, que todos os membros da Organização Mundial do Comércio protejam a propriedade intelectual conforme a Convenção de Paris e outros acordos relacionados ao tema. A abrangência das disposições denota uma posição auxiliar assumida pelo tratado da Convenção de Paris a partir desse contexto.

Para Varella (2004a, p. 3), a aprovação do Acordo sobre os Direitos de Propriedade Intelectual Relacionados ao Comércio (TRIPS), no âmbito da OMC, introduziu uma mudança paradigmática das relações Norte-Sul, favorecendo, é claro, os países do Norte. O referido autor defende a tese de que:

[...] Em um mundo globalizado, onde opera apenas um número restrito de empresas, e onde um importante desnível científico instala-se entre essas empresas, a propriedade intelectual não cumpre sua função ideal, porque não há outros produtores de tecnologia, sobretudo nos países do Sul. A função real da propriedade intelectual é, nos dias de hoje, garantir os mercados mundiais aos únicos produtores de tecnologia e impedir que os países capazes de copiar essa tecnologia o façam.
A mencionada função ideal refere-se à propalada transferência tecnológica (acesso ao conhecimento) possibilitada pelo Sistema Internacional de Patentes, mediante a obrigatoriedade de divulgação da criação pelos seus inventores à sociedade. Assim, essa função ideal seria a de permitir o conhecimento, às outras indústrias concorrentes, de como a tecnologia foi desenvolvida, para permitir que a mesma fosse reproduzida e, numa segunda etapa, melhorada. Contudo, essa transferência tecnológica depende de questões estruturais relacionadas ao grau de desenvolvimento técnico-científico dos países receptores das possibilidades abertas pelo sistema de patentes. Dessa forma, Varella (2004a, p. 3) considera que a lógica do sistema de proteção da propriedade intelectual instituída pelo TRIPS “apóia-se na idéia altamente controversa de que a proteção intelectual favorece a inovação tecnológica".

$\mathrm{Na}$ realidade atual, a produção de tecnologia está concentrada nas mãos de alguns países centrais, os quais têm não só o domínio tecnológico, mas, também, o domínio da capacidade produtiva e de mercado. Varella (2004a, p. 2), baseado na classificação de Jeffrey Sachs ${ }^{9}$, divide o mundo em três categorias de países: "os países que produzem tecnologias e obtêm patentes; os que podem adaptar esta tecnologia para sua utilização doméstica, pagando royalties; e um terceiro grupo excluído da produção e reprodução da tecnologia". Em relação aos países em desenvolvimento, ressalta determinadas regiões: 1) países com capacidade de produção de tecnologia - como certas regiões do Brasil (Sul e Sudeste), Índia (Centro), China (Costa Leste) e o México (em certos domínios específicos); 2) países com capacidade para adaptar tecnologias às suas necessidades - as outras regiões dos países da primeira categoria, além da Argentina, China e África do Sul, e 3) compõe-se dos países que estão completamente excluídos da inovação tecnológica.

O Relatório sobre o Desenvolvimento Humano do Programa das Nações Unidas para o Desenvolvimento, de 1999 , indica que $97 \%$ das patentes vêm dos países industrializados, sendo os Estados Unidos, o Japão, o Reino Unido, a França, a Alemanha e a Holanda representantes de $84 \%$ de toda a pesquisa mundial. Tal fato significa que a tecnologia de ponta elaborada é propriedade dos países desenvolvidos. Cumpre ressaltar, que mesmo neste grupo, os benefícios da pesquisa são distribuídos desigualmente,

\footnotetext{
${ }^{9}$ Artigo “A New Map of the world”. The Economist, jun. 2000.
} 
pois os Estados Unidos recebem cerca de $90 \%$ de todas as taxas pagas a título de royalties (VARELLA, 2004a).

Diante dos dados acima, verificam-se as razões que levaram os EUA a não ratificarem a $\mathrm{CDB}$, ou seja, o seu interesse em manter/assegurar a margem de lucros das empresas e de fugir da chamada repartição de benefícios (pagamentos de royalties e/ou transferência de tecnologia) imposta pela CDB, para o acesso aos recursos genéticos e desenvolvimentos de produtos na área da biotecnologia.

Essa concentração da produção de tecnologia nos países do Norte e, principalmente, nos EUA, reflete as diferenças de investimentos no domínio de produção tecnológica entre os países do Norte e do Sul. Segundo Varella (2004a, p. 1), os países do Sul não investem há mais de 30 anos mais que 3\% do total que é investido mundialmente em tecnologia, além de só possuírem $11 \%$ do total de pesquisadores. Já "os Estados Unidos investem 2,8\% do PIB na pesquisa científica, e o Brasil, um dos países do Sul que mais investe $-0,8 \%$. Em números absolutos, os investimentos americanos representam 50 vezes mais que os do Brasil”. Tais informações são compatíveis com o sentido atribuído por Santilli (2004) às relações desiguais de concentração do domínio tecnológico, ressaltando a geopolítica internacional diante do domínio biotecnológico dos países do Norte e a condição de maiores detentores da biodiversidade dos países do Sul.

Varella (2004a) sustenta que os países do Sul não têm meios suficientes para produzir novas tecnologias patenteáveis em uma proporção que possa gerar lucros consideráveis no mercado internacional. Assim, o acordo TRIPS significou, para os países do Sul, a perda de espaço lega $l^{10}$ (baseado na reciprocidade) para realização de cópias de tecnologias enquanto não participassem do Sistema Internacional de Propriedade Intelectual. Sob essa ótica, torna-se necessária uma clareza de entendimento de que a função real do TRIPS, mediante a proteção da propriedade intelectual, é garantir mercados mundiais aos principais produtores de tecnologia, impedindo que os países capazes de realizar cópias o façam.

Santos (2003) corrobora com a linha de pensamento de Varella sobre os ganhos dos países do Norte trazidos pelo acordo TRIPS e as perdas dos países do Sul. O referido autor ressalta que o surgimento desse acordo no âmbito do GATT resultou da ofensiva - dos países desenvolvidos - contrária às propostas dos países em desenvolvimento, que buscavam mudanças na Convenção de Paris de forma a flexibilizar alguns tópicos da referida convenção em prol dos países em desenvolvimento. Neste sentido, o autor assevera que:

A resistência dos países industrializados que, ao contrário da flexibilização, pretendiam discussões no sentido de reforçar a proteção à propriedade intelectual, levou a construção da proposta de que tais discussões fossem transferidas para o GATT. A primeira abordagem sobre a propriedade intelectual feita pelo GATT foi o TRIPS - Trade Related Intellectual Property Rights (Direitos da Propriedade Intelectual Relacionados ao Comércio) (sANTOS, 2003, p. 40).

O que se pode depreender é que o acordo TRIPS resulta da união de forças dos países desenvolvidos (Japão, Alemanha e EUA), orquestrada pelos Estados Unidos, visando a uniformização de forma mais rigorosa das legislações nacionais de propriedade intelectual para garantir e expandir um mercado de divisas financeiras mediante o pagamento de royalties dos países do Sul para os Países do Norte. Para os EUA, o TRIPS é uma importante estratégia de manutenção e/ou perpetuação de domínio tecnológico, tendo em vista que recebem cerca de $90 \%$ de todas as taxas pagas a título de royalties no mercado mundial.

Essa situação de domínio tecnológico mediante instrumentos de patentes ainda é mais estratégica no setor da indústria biotecnológica, tendo em vista que:

[...] poucos produtos podem ser desenvolvidos, testados, aprovados por agências reguladoras e colocados nos mercados em tempo de gerar caixa suficiente para salvar a maioria das empresas de biotecnologia. Para muitas empresas, a patente vem a ser o produto - produto que pode ser exibido à comunidade de investidores, para seduzi-los a aplicar mais fundos, ou o produto que pode ser literalmente vendido para outras empresas (DUTFIELD, 2004, p. 61).

\footnotetext{
${ }^{10}$ Varella (2004a) relata que alguns autores qualificam esse sistema de reciprocidade como "sistema de cópias legais".
} 
Assim, depreende-se que a patente é um instrumento de manutenção de domínio tecnológico e, também, uma ferramenta estratégica no âmbito financeiro (investimento/ ações) que assegura mercado para as empresas de biotecnologia.

De acordo com Varella (2004a, p. 8), o Brasil não possuía legislação de proteção intelectual sobre os produtos e processos farmacêuticos até 1988, pois, a partir do governo Vargas, essa legislação foi suspensa no país para estimular o crescimento da indústria local. Nesse contexto, o país era o sétimo maior consumidor mundial. Tal situação levou os EUA a pressionar o governo brasileiro para instauração de uma legislação de proteção da propriedade intelectual (face à resistência brasileira), mediante "sanções comerciais unilaterais, impondo taxa de $100 \%$ ad valorem sobre a produção de papel-celulose, produtos químicos e eletroeletrônicos". Em decorrência dessas sanções, foi apresentado, em 1990, ao Congresso Nacional, pelo presidente do Brasil, um projeto de lei prevendo a patenteabilidade na indústria farmacêutica, que representa o principal setor da indústria biotecnológica mundial. E como resultado final dessa correlação de forças no âmbito internacional referente ao acordo TRIPS, o Brasil aprovou em 1995 a referida Lei.

Segundo Santos (2003), para os países da América Latina como o Brasil, o reforço da atual divisão de poderes criada pelo acordo TRIPS passa a obstaculizar as tendências desenvolvimentistas que marcam sua história desde 1930. Dessa forma, é de interesse da América Latina evitar que as portas do desenvolvimento tecnológico lhe sejam fechadas. Contudo, esse fechamento é o objetivo do TRIPS quando propõe novas regras de jogo na economia mundial.

Varella (2004a, p. 3) ressalta que os países interessados na construção de um sistema global de propriedade intelectual obtiveram bastante sucesso em seus objetivos, tendo em vista que: "antes do acordo TRIPS, somente 40 países aceitavam algum sistema de propriedade intelectual em certos domínios, como produtos e processos farmacêuticos, seres vivos e circuitos integrados. Hoje, sete anos após a entrada em vigor do acordo de Marraquesh, este número está em mais de 140 países”.
Assim, a formação de um sistema mundial de propriedade intelectual, enquanto sistema de controle do conhecimento mundial no âmbito da OMC, traz efeitos nocivos para os países em desenvolvimento em muitas áreas, tendo em vista que o acordo TRIPS facilitará às multinacionais terem o domínio do mercado mundial ${ }^{11}$. Nesse sentido, Varella (2004a, p. 3) elucida que:

Muitas conseqüências negativas podem ser identificadas: o aumento dos preços protegidos, o fechamento das indústrias em diversos países, a perda de empregos. Uma vez que as empresas obtiveram o monopólio da comercialização, elas podem aumentar os preços ou praticar preços homogêneos no mundo inteiro, já que o sistema normativo proíbe a concorrência. [...] O fechamento das indústrias e a perda de empregos vêm da centralização da produção em alguns grandes centros, considerando que as indústrias podem aumentar os preços e que, não submetidas à concorrência, elas podem fechar as indústrias periféricas para fazer economia.

O referido autor ressalta que, dentre os setores mais afetados nos países pobres e em desenvolvimento, destacase a saúde pública, tendo em vista a questão do monopólio comercial dos produtos farmacêuticos.

Varella (2004a) também adverte que na etapa atual da evolução do direito internacional já não é mais possível aos países do Sul não ter uma norma de propriedade intelectual, a não ser que haja mudança no acordo TRIPS, o que para ele é pouco provável que aconteça. Desse modo, considera que esses países devem aprofundar o estudo sobre os instrumentos de propriedade intelectual, visando conhecer as possibilidades jurídicas abertas no acordo para tentar reduzir os efeitos negativos da propriedade intelectual sobre os processos de desenvolvimento tecnológico desses países, além dos efeitos nocivos relacionados à saúde pública. Nesse sentido, o referido autor defende ser necessário conhecer as possibilidades jurídicas abertas no acordo TRIPS, visando flexibilizar e/ou adaptar as normas aos interesses dos países do Sul. Considera que os Estados nacionais devem criar mecanismos de flexibilidade para

\footnotetext{
${ }^{11}$ Dentre as organizações internacionais e científicas que denunciam os efeitos nocivos da propriedade intelectual destacam-se diversas Instituições das Nações Unidas, tais como: o PNUD, a FAO e a OMS, assim como os cientistas que ganharam o prêmio Nobel - Sem em 1998 e Stiglits em 2001 (VARELLA, 2004 a).
} 
atuar a favor do desenvolvimento desses países, tendo em vista que o TRIPS exige dos países membros da OMC a adoção de um conjunto mínimo de regras de proteção da propriedade intelectual para estarem de acordo com as regras internacionais. As possibilidades jurídicas de flexibilização do acordo TRIPS em favor dos países do Sul podem ser visualizadas nos artigos 8, 27 e 31 do referido acordo, tendo em vista que:

O artigo 8, sobre os princípios gerais, dá a possibilidade de adotar medidas favoráveis a situações especiais. $\mathrm{O}$ artigo 27, ao fixar a definição de produtos patenteáveis, deixa ao mesmo tempo contornos do que se poderia excluir da patenteabilidade, e então se copiar e se adaptar livremente. Enfim, o artigo 31, fixando as licenças nãovoluntárias, torna possível a utilização dos produtos patenteados em favor de certas emergências (VARELLA, 2004a, p. 12).

Esses princípios gerais e/ou objetivos do TRIPS, ressaltados pelo autor, referem-se "a promoção do desenvolvimento tecnológico, o bem-estar social e econômico, o equilíbrio entre os direitos e obrigações, o respeito à saúde pública e o não abuso de direitos por parte dos titulares das patentes" (varella, 2004a, p. 43). Outras duas possibilidades jurídicas do direito de patentes indicadas pelo autor são: 1) a permissão ou proibição da importação paralela ${ }^{12} ; 2$ ) a obrigação da fabricação local ${ }^{13}$. Tais recursos podem ser utilizados de forma a flexibilizar as regras mínimas do acordo TRIPS, na tentativa de adaptar tais regras aos interesses dos países do Sul. Sob essa perspectiva, depreende-se que a habilidade política e jurídica dos países do Sul para saber utilizar as possibilidades jurídicas abertas no acordo TRIPS, constituem-se como ferramentas estratégicas para garantir o desenvolvimento econômico, científico e tecnológico dos mesmos. Contudo, Varella (2004a) ressalta que a flexibilidade encontrada no TRIPS, principalmente sobre o setor farmacêutico, não são conhecidas e/ou não utilizadas pela maioria dos países do Sul, que preferem seguir os critérios de propriedade intelectual utilizados pelos países do Norte.

O Brasil não aceita patentes de plantas, animais ou de parte de plantas ou de animais (existe uma legislação específica sobre proteção de cultivares). O Brasil também instituiu, em sua lei de propriedade industrial, a obrigatoriedade da produção local dos produtos patenteados, assim como a licença não voluntária (ou obrigatória) ${ }^{14}$. Esses dispositivos estão fundamentados no artigo 30 do TRIPS, o qual "garante aos Estados o direito de limitar os direitos dos titulares de patentes, sem causar prejuízos injustificados aos seus interesses legítimos" (VARELlA, 2004a, p. 43).

Varella (2004a, p. 59), analisando a situação do setor biotecnológico da economia referente à indústria farmacêutica, ressalta a utilização dos instrumentos de flexibilização do TRIPS, tais como a licença obrigatória e a obrigatoriedade de produção local, advertindo que tais instrumentos só cumprem sua função se realmente existirem condições de produção local para o medicamento licenciado e, também, se for possível importá-lo de um outro país que ofereça um melhor preço. Entretanto, “com raras exceções, como Brasil, Índia, Cuba, México e China, quanto aos medicamentos em geral, e outros países, quanto aos medicamentos específicos, os países do Sul não têm meios tecnológicos e financeiros de reproduzir localmente os produtos farmacêuticos de que precisam".

Desse modo, mesmo que o TRIPS ofereça certa possibilidade de flexibilização de suas normas em favor dos países do Sul, o referido autor assevera que "as normas de propriedade intelectual impõem aos países do Sul condições severas, nocivas ao seu desenvolvimento. Elas são contrárias às necessidades de transferência de tecnologia e à reprodução da tecnologia no Sul" (VARELLA, 2004a, p. 60).

Assim, diante da aprovação do TRIPS, restou aos países do Sul, como o Brasil, aceitar o fato de não haver condições para simplesmente recuar da adoção de um

\footnotetext{
${ }^{12}$ É um recurso utilizado, em certas legislações, que possibilita a importação dos produtos patenteados, não levando em consideração o eventual monopólio da comercialização conferido ao titular da patente ou do licenciado da exploração. Tendo em vista que as empresas e seus licenciados praticam preços diferentes, sobre mercados diferentes, isso possibilita a importação de um produto patenteado onde ele for vendido por melhor preço do que o preço do mercado local. Os países do Sul podem permitir a importação paralela para terem acesso a medicamentos mais baratos (VARELLA, 2004a).

${ }^{13}$ Essa medida vincula a concessão da patente com a obrigação da fabricação do produto no território local da obtenção da mesma, visando evitar o fechamento de indústrias decorrente da monopolização comercial do produto patenteado.

${ }^{14}$ Licenças não-voluntárias são concedidas pelo Estado sem a autorização do titular da patente. Essas licenças são de três tipos: 1) licenças concedidas para atender a um interesse público, independente do titular da patente; 2) licenças decorrentes de um comportamento abusivo ou anticoncorrencial do titular da patente; 3) aquelas que têm finalidade de permitir a exploração de uma outra patente (vARELLA, 2004a).
} 
sistema de patentes. Contudo, torna-se necessário inserir nos textos das Leis nacionais, aspectos que possibilitem reduzir ao máximo os impactos negativos sobre a atividade produtiva interna e sobre os interesses dos consumidores desses países, visando a construção de mecanismos que possibilitem a implementação do princípio de repartição de benefícios previsto na CDB e que vem sendo obstaculizado pelo Acordo TRIPS.

Conforme Dutfield (2004), na quarta sessão da Conferência Ministerial da OMC ocorrida em Doha, em dezembro de 2001, foi adotada uma declaração ministerial que instruiu algumas medidas ao programa de trabalho do Conselho TRIPS, solicitando que fosse examinado, entre outros pontos, a relação entre o Acordo TRIPS e a Convenção sobre a Diversidade Biológica, a proteção ao conhecimento tradicional e ao folclore. Como forma de contribuição ao referido exame, alguns países em desenvolvimento (Brasil, China, Cuba, Equador, Índia, Paquistão, República Dominicana, Tailândia, Venezuela, Zâmbia e Zimbábue) apresentaram, em conjunto, em junho de 2002, uma proposta em forma de documento ao Conselho do TRIPS, que visava fazer com que o sistema de patentes fosse um apoio às disposições de acesso e repartição de benefícios da CDB. Esse documento propôs que o TRIPS recebesse emendas para estipular que os Estados-membros da OMC passassem a exigir:

que um candidato a uma patente relacionada com materiais biológicos ou conhecimento tradicional apresente, como condição para adquirir direito a ela: (i) divulgação da fonte e país de origem do recurso biológico e do conhecimento tradicional usado na invenção; (ii) evidência de consentimento prévio informado, por meio da aprovação das autoridades sob regimes nacionais relevantes; e (iii) evidência de repartição justa eqüitativa de benefícios, de acordo com o regime nacional do país de origem (DUTFIELD, 2004, p. 87).

Observa-se que os chamados países do Sul e/ou megadiversos uniram-se para tentar flexibilizar as disposições do TRIPS em favor de seus interesses, apresentando uma proposta que tenta conciliar o estado atual de relacionamento entre o sistema de patentes e o acesso e repartição de benefícios previstos na $\mathrm{CDB}$.
Assim, com base na abordagem feita até o momento, verifica-se que a consolidação do Sistema Internacional de controle sobre a produção e transferência de tecnologia, mediante o acordo TRIPS no âmbito da Organização Mundial do Comércio (OMC), constitui-se numa estratégia de controle e domínio tecnológico por parte dos países desenvolvidos (Norte) e detentores das patentes tecnológicas. As regras mínimas de controle e proteção da propriedade intelectual previstas no TRIPS impõem condições de desvantagem de desenvolvimento tecnológico para os países em desenvolvimento (Sul). Diante dos processos globais de produção, comercialização e transações financeiras, esse acordo é imposto aos países como uma espécie de código de conduta nas relações econômicas, referente ao acesso às tecnologias de ponta.

$\mathrm{Na}$ outra ponta desse processo de globalização, observa-se que o acordo voltado para as ações globais de conservação da biodiversidade, mediante a Convenção da Diversidade Biológica (CDB), instituiu um código de conduta ambiental internacional, o qual se configura como um conjunto de preceitos normativos que - de forma contraditória aos objetivos do TRIPS - visa proteger e conservar a biodiversidade e a diversidade cultural (conhecimentos e modo de vida das populações tradicionais) mediante uma justa repartição de benefícios no âmbito das transferências tecnológicas entre os países do Norte e do Sul.

Assim, as normas referentes à proteção da propriedade intelectual no âmbito do TRIPS visam regular o acesso à tecnologia entre os países, e as normas da $\mathrm{CDB}$ visam regulamentar o acesso à biodiversidade e aos conhecimentos tradicionais associados ao uso dessa biodiversidade pelas populações tradicionais dos países do Sul. Observa-se que esses processos de regulamentações nos âmbitos econômico e ambiental da sociedade capitalista global sinalizam para processos contraditórios, que incidem sobre as possibilidades de efetivação de novos rumos de um "desenvolvimento sustentável" apregoado no âmbito da Organização das Nações Unidas - voltada para o desenvolvimento humano e meio ambiente.

O que está por trás desses processos contraditórios são determinadas óticas de desenvolvimento sustentável, sejam aquelas voltadas apenas para uma nova roupagem verde da mesma lógica excludente e socialmente injusta, ou aquelas afinadas com as perspectivas de um ecodesenvolvimento que realmente viabilize a instauração de uma nova lógica 
e/ou racionalidade produtiva, ou seja, uma racionalidade ambiental que busque não só o desenvolvimento econômico, mas, também, o desenvolvimento social, cultural e tecnológico.

\section{Propriedade intelectual e desenvolvimento sustentável na Amazônia brasileira: a questão do acesso aos recursos genéticos da biodiversidade}

O Brasil concentra em seu território a maior biodiversidade de organismos e de ecossistemas do globo, lidera o ranking da biodiversidade de plantas, peixes de água doce e mamíferos; ocupa a segunda posição na diversidade de anfíbios; a terceira em aves e a quinta em répteis. Destaca-se que a floresta tropical úmida - que cobre cerca de $7 \%$ do planeta - contém, segundo estimativas, cerca de $50 \%$ da biodiversidade mundial. A Amazônia brasileira, com 5 milhões de $\mathrm{km}^{2}$, ocupa $80 \%$ da Amazônia ${ }^{15}$ e representa um percentual de $67 \%$ das florestas tropicais do mundo (HAGLER, 2003).

No âmbito do desenvolvimento da economia global do conhecimento, vem sendo destacada a importância econômica da biodiversidade da Amazônia, tendo em vista que o setor biotecnológico assume lugar de destaque nessa fase atual da internacionalização da economia. Há uma difusão ideológica sobre o "potencial" econômico incalculável da biodiversidade, principalmente no setor farmacêutico.

[...] A crescente demanda por produtos químicos e fármacos aumentou o interesse sobre a biodiversidade existente nas áreas silvestres pouco ou ainda não exploradas, como no caso da Amazônia. A indústria farmacêutica recentemente retomou o entendimento de que a cura de milhares de enfermidades humanas pode estar nos produtos extraídos dos recursos naturais biológicos das florestas tropicais, o que está fazendo com que suas atenções voltem então para o nosso país. (sANTOS, 2003b, p. 4).
Observa-se a formação de um consenso, no âmbito das discussões voltadas para o desenvolvimento econômico, de que, no século XXI o mercado mundial abre perspectivas totalmente inovadoras no campo biotecnológico, direcionando esforços na busca de novos bioprodutos para fins medicinais, cosméticos, suplementos nutricionais, produtos agrícolas, entre outros, tendo em vista o surgimento de um mercado voltado ao prolongamento da vida com qualidade.

Só em 1998, os medicamentos movimentaram 300 bilhões de dólares em todo o mundo, sendo que $40 \%$ dos produtos têm origem direta ou indiretamente de fontes naturais. No Brasil, as vendas atingiram a marca de 11 bilhões de dólares, havendo ainda um espaço enorme para ampliação desse mercado. O Instituto de Pesquisa Econômica Aplicada (IPEA) estimou em pelo menos 2 trilhões de dólares o valor potencial do banco genético brasileiro (PEREIRA; FILIZOLA, 2004).

Difunde-se na mídia uma enorme alusão ao potencial econômico da megabiodiversidade brasileira e, principalmente, da Amazônica. Essa ênfase às potencialidades econômicas da biodiversidade brasileira e a realidade da escassez dos recursos naturais no restante do mundo, conjuntamente com a falta de recursos para fiscalizar a grande extensão territorial do Brasil, têm levado à biopirataria - que é o comércio ilegal da biodiversidade (SANT'ANA, 2004). Contudo, tal infração não é nova, pois a evasão do patrimônio genético brasileiro vem ocorrendo desde o descobrimento do país, com a retirada de suas riquezas naturais. Mas, as técnicas de engenharia genética da biotecnologia moderna passaram a possibilitar o aumento da biopirataria, tendo em vista que a informação genética pode ser extraída dos recursos da biodiversidade para ser manipulada em outras localidades, sem precisar levar o próprio recurso biológico fonte dessa informação. Assim, instauram-se processos de biopirataria de difícil controle por parte dos órgãos de fiscalização ambiental.

Conforme Lopes (2001), a Floresta Amazônica, deixada à própria sorte, tenderá ao mesmo fim das

\footnotetext{
${ }^{15}$ Conforme Becker (2001), a Amazônia é uma região sul-americana que corresponde a 2/5 da América do Sul, 1/5 da disponibilidade mundial de água doce, 1/3 das reservas mundiais de florestas latifoliadas. Em termos de ocupação demográfica, corresponde a apenas 3,5 milésimos da população mundial, contendo a maior riqueza em biodiversidade e o maior banco genético do planeta. Destaca-se que $63,4 \%$ da Amazônia estão sob a soberania do Brasil.
} 
florestas dos países desenvolvidos, exemplificado entre nós pela dramática redução de área da Mata Atlântica nos últimos quinhentos anos. Assim, uma proposta de desenvolvimento para a Amazônia deve configurar um conjunto coordenado de ações socioeconômicas e culturais, que visem a conservação da riqueza biológica existente, ao mesmo tempo em que promova a integração amazônica, mediante processo de desenvolvimento sustentável, com base no que melhor podem oferecer ciência e tecnologia à exploração racional das riquezas da floresta.

As preocupações referentes à defesa e conservação da biodiversidade no Brasil foram incluídas na Constituição de 1988. A retomada das iniciativas para a conservação da biodiversidade ocorreu com a assinatura da Convenção sobre Diversidade Biológica (CDB) em 1992, e sua ratificação em 1994. A CDB passou a reafirmar a soberania dos países sobre seu patrimônio genético, e os países signatários se comprometeram a facilitar o acesso a esses recursos, mediante a condição de consentimento prévio e de comum acordo com as partes interessadas. A CDB prevê também que os países que usarem recursos genéticos originários de outras nações devem garantir a repartição eqüitativa de seus benefícios econômicos.

Apesar da importância estratégica que a questão do acesso aos recursos genéticos tem para o desenvolvimento sustentável do Brasil, essa matéria ainda é regulamentada por via da Medida Provisória 2.186 de 2001. Tal situação por si só já denota um atraso na busca de caminhos para o uso racional e democrático do acesso aos recursos genéticos. Conforme Lopes (2001, p. 7), "os pontos centrais de um regime de acesso aos recursos genéticos são a conservação e o aproveitamento sustentável da biodiversidade, ou seja: a regulamentação do seu acesso, compreendendo a forma de contratos e a proteção de todos os direitos de propriedade intelectual envolvidos, inclusive a relativa aos conhecimentos tradicionais".

Para Varella (2003), o conjunto de normas federais e estaduais, assim como o projeto de lei de acesso à biodiversidade em andamento (que representa um dos mecanismos de implementação das diretrizes previstas na Convenção da Diversidade Biológica), mostra-se pouco eficiente para promover um desenvolvimento sustentável a partir do uso dos recursos genéticos. Desde a ratificação da Convenção da Diversidade Biológica e da Lei de Patentes, a discussão sobre o acesso aos recursos genéticos tomou um lugar de importância estratégica para o desenvolvimento do país. O assunto ganhou a mídia e o domínio público, demonstrando que sua regulação se tornou indispensável. Contudo, as partes interessadas (Estado, empresas, comunidade científica, além de grupos ambientalistas) não se mostraram organizadas o suficiente para lograrem normas democráticas e, "enquanto todos os países do mundo ricos em biodiversidade fizeram diversos contratos de acesso aos recursos genéticos, conseguindo importantes recursos, o Brasil, o país de maior diversidade biológica, ainda tem uma participação tímida" (VARELLA, 2003, p. 25).

O conjunto de normas existente no Brasil, em nível constitucional da União e dos Estados, envolve tanto normas de natureza ambiental, propriamente ditas, assim como normas de direito de propriedade intelectual relacionadas à proteção da natureza. Contudo, conforme Varella (2003), um estudo da evolução desse conjunto de normas no que se refere à questão do acesso aos recursos genéticos, tem mostrado que a evolução das normas de propriedade intelectual vem de encontro com a evolução das necessidades do direito ambiental. Tal situação decorre de uma falta de integração sistêmica entre as referidas normas no âmbito da legislação interna do Brasil.

No direito interno, não há como separar o direito de propriedade intelectual do direito ambiental, em se tratando de proteção do controle do acesso aos recursos genéticos. O direito de propriedade intelectual é rico em instrumentos que lhe são próprios e possui uma lógica que, quando dominada, tem o poder de garantir ao operador jurídico a habilidade de promover o desenvolvimento local a partir dos recursos naturais. Infelizmente esta capacidade tem sido mal aproveitada no Brasil, pois os operadores jurídicos especialistas em cada um destes temas não têm trabalhado em conjunto (VARELla, 2003, p. 4).

Diante da consolidação do Sistema Internacional de Propriedade Intelectual mediante o acordo TRIPS, essa proposta de utilização de instrumentos jurídicos de propriedade intelectual conjuntamente com os preceitos do direito ambiental sinaliza para uma estratégia de proteção e/ou redução das desvantagens dos países do Sul no desenvolvimento da biotecnologia. Como exemplo, cumpre ressaltar a estratégia que os países do Sul (ricos em diversidade biológica) poderiam utilizar, tal como o argumento de "excluir a proteção das invenções derivadas 
de organismos vivos que não fossem acompanhadas de um contrato de divisão de benefícios com os países de origem deste organismo, conforme os dispositivos da Convenção sobre Diversidade Biológica" (VARELla, 2003, p. 18). Dessa forma, os países megadiversos poderão, com base na obrigatoriedade de implementação da Convenção da Biodiversidade, exigir "que os contratos de acesso aos recursos genéticos sejam apresentados aos escritórios de patentes, sob pena de exclusão da patenteabilidade no interior do território. Isso pode representar a exclusão de um número importante de produtos hoje patenteados" (ibidem). $\mathrm{O}$ autor ressalta que o TRIPS não evoca essa possibilidade, contudo, não impede que um país membro a torne obrigatória.

É fato que o Brasil, assim como a maioria dos países do Sul, vivencia limitações quanto ao exercício pleno da sua soberania, em virtude da sua inserção de forma subalterna numa situação de crescente globalização de atividades e de fluxos financeiros. Dessa forma, faz-se necessário que os países em desenvolvimento lutem para tentar flexibilizar os dispositivos desse acordo, tanto em âmbito externo quanto no âmbito interno. Neste âmbito, ficou clara a necessidade de se saber utilizar as possibilidades jurídicas abertas no TRIPS, mediante um trabalho conjunto que envolva tanto os preceitos do direito de propriedade intelectual quanto ambiental. Essa pode ser uma estratégia para se vislumbrar as possibilidades de uso sustentável da biodiversidade brasileira e, especialmente, da amazônica.

No âmbito regional da Amazônia Brasileira, o Ministério do Meio Ambiente e da Amazônia Legal implantou, em 1997, o Programa Brasileiro de Ecologia Molecular para Uso Sustentável da Biodiversidade da Amazônia (PROBEM/Amazônia). O referido programa visou contribuir para o desenvolvimento da bioindústria no país e em especial na região, buscando a geração de conhecimento e transferência de tecnologia de ponta, mediante diversas modalidades de parcerias com instituição de pesquisa e o setor privado. O Centro de Biotecnologia da Amazônia (CBA) foi criado no âmbito do PROBEM/ Amazônia, e inserido na Política Industrial, Tecnológica e de Comércio Exterior no ano de 2004.

De acordo com Oliveira (2005), o objetivo do CBA é desenvolver produtos e processos a partir de elementos da biodiversidade da Amazônia. Para atingir tal propósito, o mesmo recorrerá ao conhecimento desenvolvido em universidades e centros de pesquisa, visando incentivar e apoiar a criação de empresas de biotecnologia (incubadora de empresas). A meta inicial é investir em testes farmacológicos, de toxicologia, fitoterápicos, de cosméticos, de inseticidas e do aproveitamento nutritivo e terapêutico de frutas.

Assim, o chamado "potencial" econômico da megabiodiversidade da Amazônia brasileira representa uma aposta no futuro do desenvolvimento local e regional. Contudo, o futuro desse desenvolvimento depende do formato político da gestão das potencialidades desse uso econômico da biodiversidade, o que está diretamente relacionado com o processo da gestão do fomento do desenvolvimento da biotecnologia e da bioindústria. Acredita-se que o foco de desenvolvimento de novos bioprodutos pode gerar uma incalculável lucratividade no mercado internacional. Entretanto, de nada adiantará obter tais lucros se não implicarem em benefícios sociais, principalmente, às comunidades locais e, em especial, aquelas que detêm o conhecimento tradicional sobre a biodiversidade.

\section{Considerações finais}

O desenvolvimento sustentável da Amazônia é um desafio de grande complexidade, pois deve gerar progresso econômico e social, a partir do uso sustentável dos componentes de sua biodiversidade, gerando emprego e renda para as populações que vivem nas zonas rurais, buscando ocupação racional sem devastar a floresta e, principalmente,

promover a integração cultural de comunidades locais e indígenas ao processo, sem desfigurá-las nas suas tradições e sem perder o muito que podem adicionar às civilizações ditas avançadas, pelo seu conhecimento e pelas suas práticas ajustadas a uma existência de equilíbrio com o seu meio ambiente (LOPES, 2001, p. 3).

A chamada economia da floresta em pé, defendida pelos movimentos de defesa e conservação da biodiversidade, requer ações efetivas que possibilitem novas alternativas de geração de renda a partir da floresta. Essas alternativas devem visar a valorização da biodiversidade ainda existente, configurando-se em alternativas que não se apresentem em 
condições de desvantagem em relação às práticas agrícolas e agroflorestais baseadas na substituição da floresta, ao mesmo tempo em que possibilitem a recuperação econômica de grandes extensões de áreas degradadas, criadas a partir de tecnologias inadequadas às condições naturais existentes (PEREIRA; FILIZOLA, 2004. p. 13).

Foi possível depreender das abordagens apresentadas que os parâmetros que hoje orientam a competição mundial estão assentados no domínio do conhecimento, enquanto força de inovação do processo produtivo. Assim, o novo paradigma técnico-científico de produção tem no progresso da inovação tecnológica a base de competitividade no mundo atual da globalização econômica. Portanto, a proteção da propriedade intelectual transformou-se numa arma poderosa na guerra por mercados.

Desse modo, entende-se que a consolidação de um sistema mundial de propriedade intelectual resultou

\section{Referências}

BARBOSA, Denis Borges. Uma introdução à propriedade intelectual. Disponível em: <http://www.inforjur.cc.ufsc.br/ artigo.asp>. Acesso em: 26 dez. 2003.

FONSECA, Renato. Inovação tecnológica e o papel do governo. Brasília: CNI, 2001.

HAGLER, L. G. S. M. Biodiversidade e biossegurança. Disponível em: $<$ http://www.biotecnologiaciencia\&desenvolvimento. com.br>. Acesso em: 23 jun. 2003.

LOPES, Ney. A biodiversidade como estratégia moderna de desenvolvimento da Amazônia. Disponível em: <http:// www.comciencia.br/default/htm>. Atualizado em: 10 jun.2001. Acesso em: 26 dez. 2003.

MACEDO, Maria Fernanda. Patentes, pesquisa \& desenvolvimento: um manual de propriedade industrial. Rio de Janeiro: Fiocruz, 2000. 161 p.

Propriedade intelectual em biotecnologia. In: Material didático I da disciplina de Propriedade Intelectual em Biotecnologia do Programa Multi-Institucional de Pós-Graduação em Biotecnologia da Universidade Federal do Amazonas, 2003 (mimeo).

ROMEIRO, A. R. Biodiversidade e sustentabilidade agropecuária. Disponível em: <http://www.biodiversidadebrasil. da pressão dos países desenvolvidos, principalmente dos EUA, para criar barreiras aos novos competidores emergentes dos países do sul. Ficou claro que o acordo TRIPS, na realidade, não vem cumprindo sua função ideal de realizar "transferência tecnológica" para os países do Sul. Ao contrário, constitui-se como uma estratégia dos países do Norte para garantir a perpetuação de suas condições vantajosas de domínio tecnológico.

Desse modo, diante da cobiça internacional em relação à biodiversidade amazônica e das discussões polêmicas em torno de sua utilização sustentável, torna-se necessária uma política de desenvolvimento regional que realmente efetive alternativas de uso racional e sustentado da biodiversidade local. Fica clara a necessidade dos gestores federais e estaduais compreenderem que é indispensável garantir, de forma democrática, a regulação do acesso ao patrimônio genético, como marco na utilização sustentável da biodiversidade para o desenvolvimento da Amazônia.

com.br/destaques.asp?PIN=0\&ID=477>. Acesso em: 23 jun. 2003.

SANTOS, Onélio Luis S. Considerações sobre a propriedade intelectual no processo de globalização mundial e integração regional com uma sucinta abordagem sobre sua proteção no mercosul e no Brasil. Disponível em: <http://www.nepi.adv.br/ index.htm>. Acesso em: 26 dez. 2003.

SANTOS, Antônio S. R. dos. Bioprospecção: considerações gerais. Disponível em: <http://www.nepi.adv.br/index.htm>. Acesso em: $26 \mathrm{dez} .2003 \mathrm{~b}$.

SARDENBERG, Ronaldo Mota. Tecnologia, inovação e propriedade intelectual na economia globalizada: estratégias para o setor aeroespacial. Disponível em: <http:www.aeb.gov.br/ 25072001-integradiscurso.htm>. Acesso em: 26 dez. 2003.

SINGER, Paul. Globalização e desemprego: diagnósticos e alternativas. 2. ed. São Paulo: Contexto, 1998.

SILVA, Félix Andrade da. TIB: conhecimento e informação para a capacitação tecnológica do setor produtivo brasileiro. Disponível em: $<$ http://www.nepi.adv.br/index.htm>. Acesso em: 26 dez. 2003.

VARELLA, Marcelo D. Acesso aos recursos genéticos no Brasil. In: Material didático I da disciplina de propriedade 
CHAVES, M. P. S. R.; NOGUEIRA, M. G. Propriedade intelectual, globalização e desenvolvimento:...

intelectual em biotecnologia do Programa Multi-Institucional de Pós-Graduação em biotecnologia da Universidade Federal do Amazonas, 2003 (mimeo).
A desigualdade Norte-Sul na OMC: o exemplo da propriedade intelectual. In: VARELLA, Marcelo D. Direito Internacional Econômico Ambiental. Belo Horizonte: Del Rey, 2004. 